\title{
An experimental investigation of working with ordinary and electromagnetic nozzles
}

\author{
Dimitar Kehayov ${ }^{1}$, Atanas Atanasov ${ }^{2}$ and Dan Cujbescu ${ }^{3 *}$ \\ ${ }^{1}$ Agricultural University-Plovdiv, Department of Agricultural Mechanization, 4000 Plovdiv, Bulgaria \\ ${ }^{2}$ University of Ruse, Agricultural Machinery Department, 7012, Ruse, Bulgaria \\ ${ }^{3}$ INMA Bucharest, 6 Ion Ionescu de la Brad Bld, Bucharest, Romania
}

\begin{abstract}
The great variety of plant protection equipment, the shape, length and slope of the cultivated area, the type of sprayers used and the professional skills of the operator require an individual approach to each sprayer and cultivated area. The aim of this study was to compare the area of the double-treated sections when working with ordinary and electromagnetic nozzles at different slopes of the treated area. For the analysis, actual field coverage data were used when working with the Amazone self-propelled sprayer - Pantera 4502, with a boom width of $24 \mathrm{~m}$, half of which is equipped with electromagnetic nozzles and the other half - with ordinary nozzles. It was found that when working with ordinary nozzles, the area of overlap increases with increasing degree of overlap and the angle of inclination of the section boundary. The area of overlap when using ordinary nozzles is almost 3 times larger than when using electromagnetic at $100 \%$ overlap of the treated areas. Regression models, surfaces and lines were obtained, with the help of which the area of overlap in each section of the treated field can be determined.
\end{abstract}

\section{Introduction}

Mechanized technologies in plant protection increase labor productivity, reduce relative costs, improve working conditions for workers, improve the quality of work and contribute reduce adverse effects on the environment.

More and more new techniques for growing crops are entering in our agriculture. This requires a very good knowledge of machines and technologies. Today's agriculture is inconceivable without the use of various chemical plant protection products, as well as biological and mineral fertilizers to stimulate the growth and development of crops. The great variety of machines for performing these operations imposes the need to know the capabilities of each of them, for their application in individual techniques and technologies. Reducing unintentional pesticide application errors can improve profitability and reduce the loss of pesticides and nutrients to the environment from agricultural operations. The potential for saving pesticides and fertilizers by automatically based control of spray nozzles with use ZYNX X15 control console with a 30-channel electronic sprayer is present in [5]. Other authors [4] evaluate the use of ultrasonic sensors for variable speed automatic sprayers. An important condition for quality work is to the strength calculus of the nozzles from the sprayers [1]. Uneven spraying of the working solutions during the plant protection

\footnotetext{
* Corresponding author: dcujbescu@yahoo.com
} 
operations leads to overconsumption of the working solution and failure to achieve the desired effect. In this regard, an interesting study was performed by [2, 3, 8] using a scanning system to assess the distribution of the working solution, both in the laboratory and in specific cultures in real time. The uniform spreading of the working solution on the treated area largely depends on the type of nozzle used, the angle and the spray pressure considered by $[7,9],[10]$. How to optimize the solution distribution and reduce the spray diversion is suggested by [6].

The search for optimal techniques and approaches for the implementation of an even distribution of plant protection products on the soil, plants or storages, in order to destroy or suppress weeds, diseases and pests for a certain term is the basis of the research. The great variety of plant protection equipment, the shape, length and slope of the cultivated area, the type of nozzles used, the professional skills of the operator and other influencing factors require an individual approach to each sprayer and cultivated area.

The aim of the present work is to compare the area of the double-treated places when working with ordinary and electromagnetic nozzles at different slopes of the treated area.

\section{Materials and methods}

In the present work the object of study is the self-propelled sprayer of the company Amazone - Pantera 4502. The width of the spraying system is $24 \mathrm{~m}$. It consists of 7 sections - the middle 3 have 8 nozzles with 4 m working width, the final 4 have 6 nozzles with $3 \mathrm{~m}$ working width. For the purpose of our research we have equipped half of the boom system with electromagnetic nozzles, and the other half - with ordinary ones. Observations were made for the overlap to the middle boom. Both types of nozzles are equipped with a sprayer IDK-120-03 from Lechler. The solenoid valves are manufactured by Arag (s/n 140467) The experiment was conducted in 2020 in the experimental field of the Agrarian UniversityPlovdiv. The operating speed of the sprayer in the cultivated area was $20 \mathrm{~km} / \mathrm{h}$. The influence of the field slope at $5^{0}, 35^{\circ}$ and $65^{\circ}$ and the degree of overlap at $0 \%, 50 \%$ and $100 \%$ on the overlap area when working with ordinary and electromagnetic nozzles was reported.

The area of overlap is defined as follows:

$$
\begin{aligned}
& S=\frac{a b}{2} \\
& \frac{b}{a}=\operatorname{tg} \alpha \\
& b=a \cdot \operatorname{tg} \alpha \\
& S=\frac{a^{2} \operatorname{tg} \alpha}{2}
\end{aligned}
$$

Where: a- length equal to the length of the section, $\mathrm{m}$.

$\mathrm{b}$ - length equal to the boundary of the untreated field

$\alpha$ - the angle locked between the section and the boundary of the untreated field ${ }^{\circ}$.

When operating the sprayer with conventional sprayers with $0 \%$ overlap untreated areas remain colored green. This is due to the fact that when the outer part of the section 
reaches the field boundary, the section crane switches off the operation of the whole section.

In the second variant of the test when operating the sprayer with ordinary nozzles with $50 \%$ overlap we have double-treated areas - shown in the figure in red and those that remain untreated - shown in green. During the test, 3 sections work - the first with a width of $4 \mathrm{~m}$, and the two end - with a width of $3 \mathrm{~m}$ each. The size of the double-treated sections is determined according to formula (4) at a width for side "a" for the first section is $2 \mathrm{~m}$, and for the second and third respectively $1.5 \mathrm{~m}$.

For the third test variant with $100 \%$ overlap the sectional crane switches off the section only when its entire working width has entered the already treated field. The double-treated areas are coloured red. The size of the double-treated sections is determined according to the formula (4) at "a" on the first bar $4 \mathrm{~m}$, "a" on the second and third respectively $3 \mathrm{~m}$.

When working with an electromagnetic nozzle, an experiment was performed with two variants - without overlap (0\%) and with full (100\%) overlap. What is special here is that the working width for each nozzle is $0.5 \mathrm{~m}$. When working without overlapping, the nozzle is switched off when it reaches the field boundary. At $100 \%$ overlap, the nozzle is switched off after its torch has fully entered the treated field.

\section{Results and discussion}

For working with ordinary nozzles, the following data were obtained from the calculations made in Table 1.

Table 1. Overlap area when working with ordinary nozzles, $\mathrm{m}^{2}$

\begin{tabular}{|c|c|c|c|}
\hline \multirow{2}{*}{ Overlap } & \multicolumn{3}{|c|}{ Slope at the field boundary } \\
\cline { 2 - 4 } & $5^{\mathrm{O}}$ & $35^{\mathrm{O}}$ & $65^{\circ}$ \\
\hline $0 \%$ & 0 & 0 & 0 \\
\hline $50 \%$ & 0,568 & 2,975 & 9,052 \\
\hline $100 \%$ & 1,479 & 11,9 & 36,448 \\
\hline
\end{tabular}

It was found that with increasing degree of overlap and slope of the field boundary, the area of the double-cultivated part of the field increases. As a result of the regression analysis the following model was obtained:

The model has the form:

$$
Z=0,005442 X Y
$$

Where: $\mathrm{Z}$ - double cultivated area, $\mathrm{m}^{2}$;

$\mathrm{X}$ - slope of the field boundary,

$\mathrm{Y}$ - degree of overlap, \%.

The change of the double-treated area and the lines of equal response are presented in Fig. 1. and Fig. 2. From Fig.1. it is seen that with increasing the slope of the field the double treated area increases. 


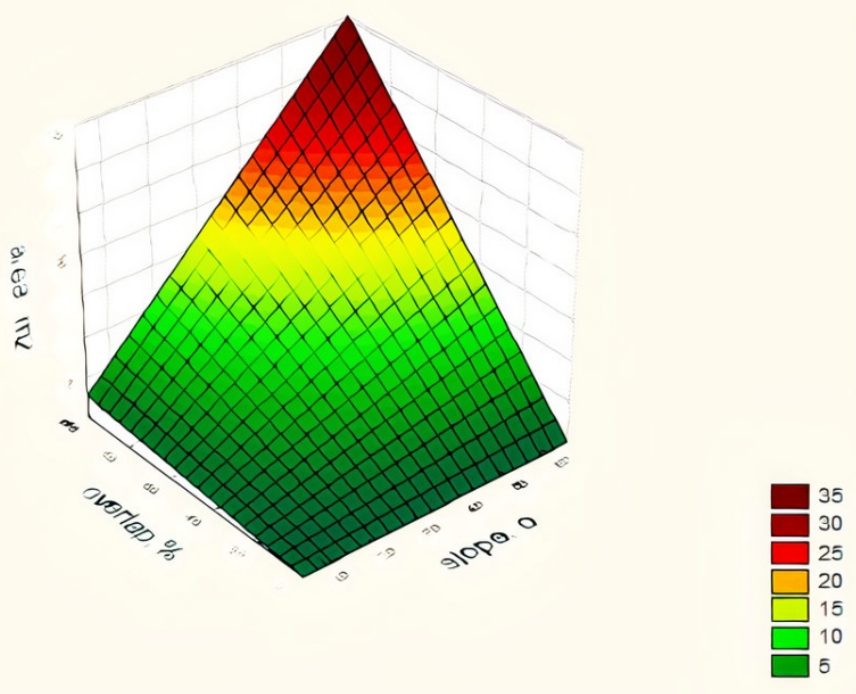

Fig.1. Variation of the double treated area

The lines of uniform response make it possible, knowing the slope of the field and the degree of overlap, to easily and quickly determine the double-treated area. For this purpose, from the point of the abscissa corresponding to the slope, we raise vertical lines. From the point of the ordinate corresponding to the degree of overlap, we draw horizontal lines. The intersection of the two lines usually lies on one of the family curves. From the scale to the right of the coloring, the double-treated area is reported.

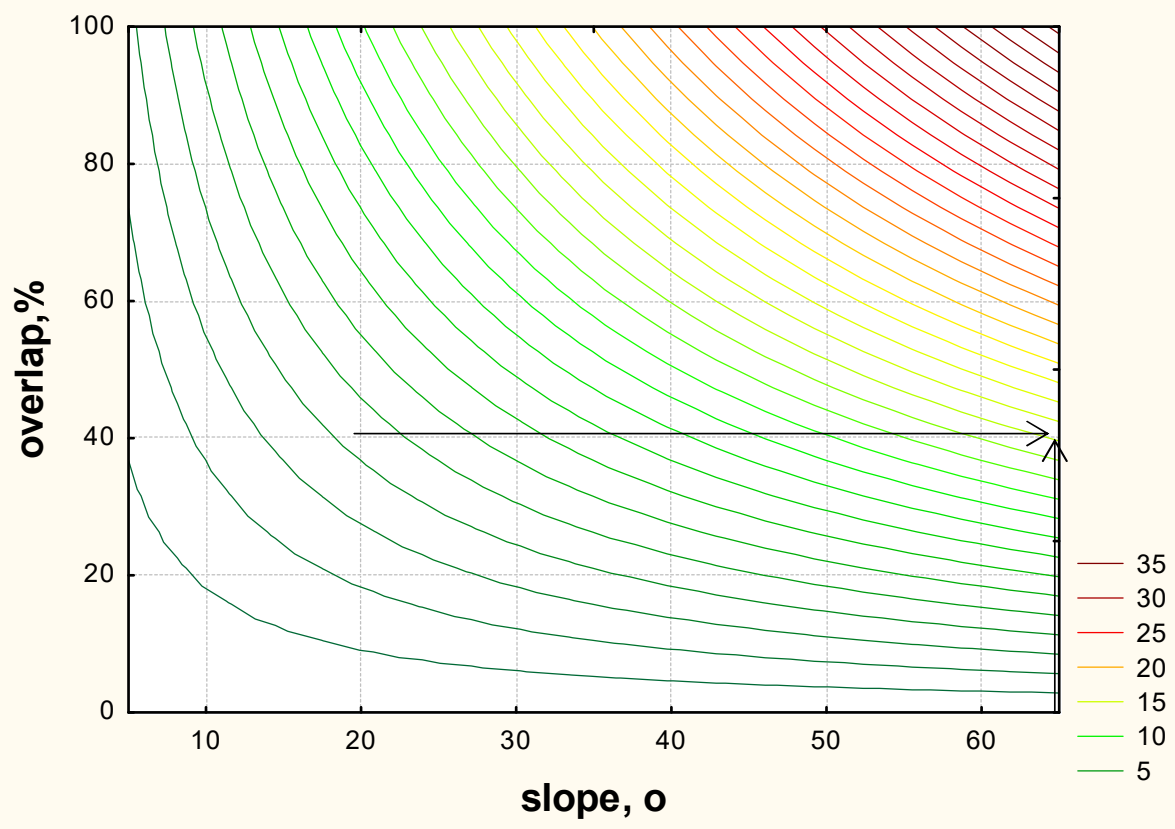

Fig.2. Lines of equal response 
Example: Let the slope be $50^{\circ}$ and the overlap be $40 \%$. After baking the horizontal and vertical lines from the respective points of the ordinate and the abscissa, their point of intersection lies on the curve corresponding to $15 \mathrm{~m}^{2}$ double treated area.

Table 2 Overlap area when working with electromagnetic nozzles, ${ }^{\mathrm{m} 2}$

\begin{tabular}{|c|c|c|c|}
\hline \multirow{2}{*}{ Overlap } & \multicolumn{3}{|c|}{ Slope at the field boundary } \\
\cline { 2 - 4 } & $5^{\circ}$ & $35^{\circ}$ & $65^{\circ}$ \\
\hline $0 \%$ & 0 & 0 & 0 \\
\hline $100 \%$ & 0,435 & 3,5 & 10,72 \\
\hline
\end{tabular}

From the obtained results Table 1 and Table 2 at 100\% overlap it was found that at different slopes of the field boundary the overlap is almost 3 times greater when working with ordinary nozzles. This is due to the fact that when working with ordinary nozzles, the entire section is switched off when it fully enters the treated field. Parameter "a" (formula 4) varies from 3 to $4 \mathrm{~m}$ depending on the working width of the section. When working with electromagnetic nozzles, each is switched off when it fully enters the already treated field, one after the other. In this case, parameter "a" has a constant size of $0.5 \mathrm{~m}$. The doubletreated area for the whole section is obtained according to formula 4 by summing the areas for each nozzle. nozzles:

The following regression models were obtained for the area of overlap of the two

$$
\begin{aligned}
& \text { S o. } n=1,5026 X^{2,9261} \\
& \text { S e.m. } n=0,4417 X^{2,9267}
\end{aligned}
$$

Where: S o.n - Overlap area when working with ordinary nozzles

S e.m.n - Overlap area when working with electromagnetic nozzles

Overlap area at $100 \%$ overlap, Series 1 - with electromagnetic nozzle, Series2 - with ordinary nozzle is shown in Fig. 3.

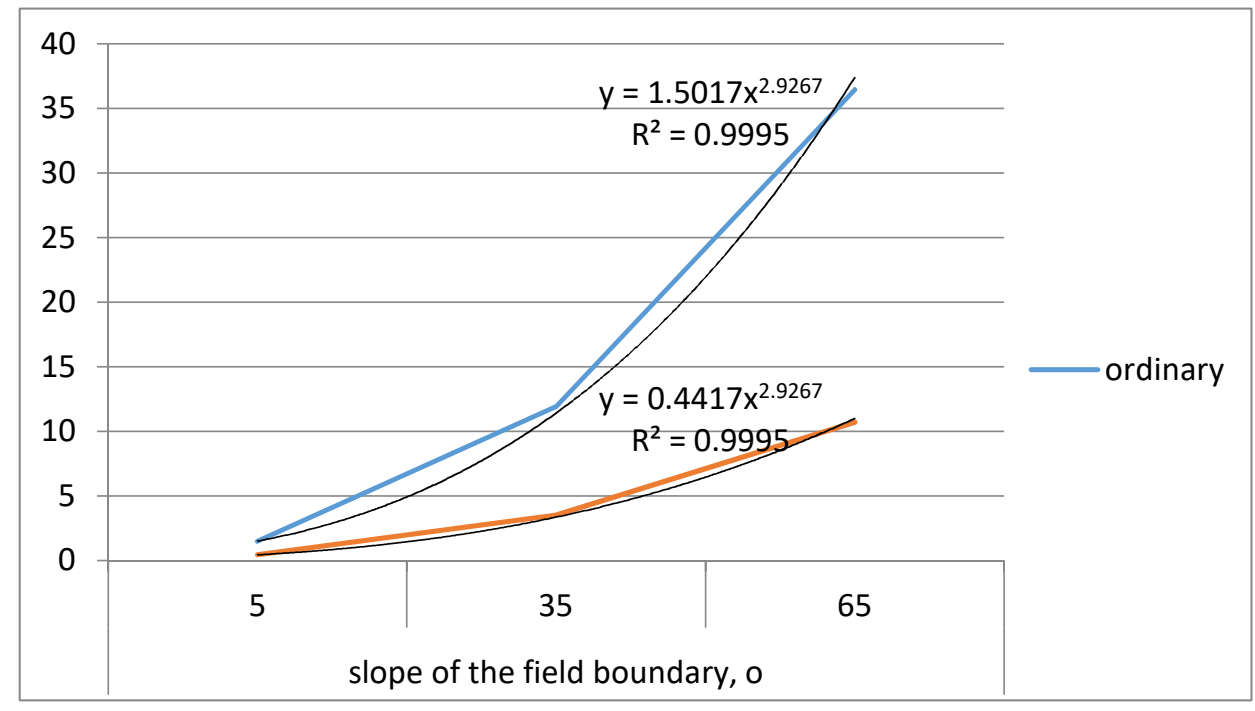

Fig.3. Overlap area with $100 \%$ overlap, $\mathrm{m}^{2}$ 


\section{Conclusions:}

1. When working with ordinary nozzles, the area of overlap increases with the increase of the degree of overlap and the angle of inclination of the section boundary;

2. The area of overlap when using ordinary nozzles is almost 3 times larger than when using electromagnetic at $100 \%$ overlap of the treated areas;

3. Regression models, surfaces and lines are obtained, with the help of which the area of overlap in each section of the treated field can be determined.

\section{References}

[1] Bungescu S., Stahli W., Biriş S., Vlăduţ V., Imbrea F., Petroman C. - Cosmos programm used for the strength calculus of the nozzles from the sprayers, proceedings of the 37 International symposium on agricultural engineering "Actual Tasks on Agricultural Engineering", Opatija - Croaţia, 2009, pp. 177-184.

[2] Emanuele Cerruto, Sabina Failla, Domenico Longo, Giuseppe Manetto, Simulation of water sensitive papers for spray analysis, AgricEngInt: CIGR Journal, Vol. 18, No. 4, 2016, pp.23-29.

[3] Heping Zhu, Masoud Salyani, Robert D. Fox, A portable scanning system for evaluation of spray deposit distribution, Computers and Electronics in Agriculture, vol.76, 2011, pp. 38-43

[4] Hong Y. Jeon, Heping Zhu, Richard Derksen, Edal Ozkan, Charles Krause, Evaluation of ultrasonic sensor for variable-rate spray applications, Computers and Electronics in Agriculture vol.75, 2011, pp. 213-221.

[5] J.D. Luck, S.K. Pitla, S.A. Shearer, T.G. Mueller, C.R. Dillon, J.P. Fulton, S.F. Higgins, Potential for pesticide and nutrient savings via map-based automatic boom section control of spray nozzles, Computers and Electronics in Agriculture, vol.70, 2010, pp.19-26.

[6] Jan C. van de Zande, J. F. M. Huijsmans, H. A. J. Porskamp, J. M. G. P. Michielsen, H. Stallinga, H. J. Holterman A. de Jong, Spray techniques: how to optimise spray deposition and minimise spray drift, Environmentalist, 2008, vol. 28, pp.9-17.

[7] Nasir .S. Hassen, Nor Azwadi .C. Sidik, Jamaludin .M. Sheriff, Effect of nozzle type, angle and pressure on spray volumetric distribution of broadcasting and banding application, Journal Mechanical Engineering Research, vol.5 (4), pp.76-81.

[8] Qamar Uz Zaman, Travis J. Esau, Arnold W. Schumann, David C. Percival, Young Ki Chang, Scott M. Read, Aitazaz A. Farooque, Development of prototype automated variable rate sprayer for real-time spot-application of agrochemicals in wild blueberry fields, Computers and Electronics in Agriculture vol.76, 2011, pp. 175-182.

[9] Roşu (Niţu) M., MatacheM., Vlăduţ V., Căsăndroiu T., Bungescu S. - Influenceof the jet's angle size on the spraying process, proceedings of the 43 International symposium on agricultural engineering "Actual Tasks onAgricultural Engineering", 2015 pp. 275-286.

[10] Vlăduţ V., Matache M., Voicea I., Găgeanu P., Bungescu S.,Biriş S., Mihailov N., Popescu S., Savin L. - Comparison of a sprinkler's transverse distributionwith used and new nozzles, proceedings of the 39 International symposium on agricultural engineering "Actual Tasks on Agricultural Engineering",, Opatija - Croaţia, 2011, pp. 307-312, 